\title{
Long-Term Outcomes of Cardiac Rehabilitation in Diabetic and Non-diabetic Patients With Myocardial Infarction
}

\author{
Hyun Jun Kim, MD ${ }^{1,2}$, Min Cheol Joo, $\mathrm{MD}^{1,2}$, Se Eung Noh, $\mathrm{MD}^{1,2}$, Ji Hee Kim, MD ${ }^{1,2}$ \\ ${ }^{1}$ Department of Physical Medicine and Rehabilitation, Wonkwang University School of Medicine, Iksan; \\ ${ }^{2}$ Regional Cardiocerebrovascular Center, Wonkwang University Hospital, Iksan, Korea
}

Objective To investigate the long-term outcomes of cardiac rehabilitation (CR) on exercise capacity in diabetic (DM) and non-diabetic (non-DM) patients with myocardial infarction (MI).

Methods Of the MI patients who received hospital-based CR from February 2012 to January 2014, we retrospectively reviewed the medical records of the patients who continued follow-up through the outpatient clinic and community-based self-exercise after CR. A total of 37 patients (12 with DM and 25 without DM) were included in this study. Exercise capacity was measured by symptom-limited exercise tests before and after hospital-based CR and 1 year after the onset of MI.

Results Before the CR, the DM group had significantly lower exercise capacity in exercise times, peak oxygen consumption $\left(\mathrm{VO}_{2 \text { peak }}\right)$, and metabolic equivalent tasks (METs) than did the non-DM group. After the CR, both groups showed significantly improved exercise capacity, but the DM group had significantly lower exercise capacity in exercise times, submaximal rate pressure products $\left(\mathrm{RPP}_{\text {submax }}\right), \mathrm{VO}_{\text {2peak }}$, and METs. One year after the onset of the MI, the DM group had significantly lower exercise capacity in exercise times, $\mathrm{RPP}_{\text {submax }}$, and $\mathrm{VO}_{\text {2peak }}$ than did the non-DM group, and neither group showed a significant difference in exercise capacity between before and after the CR.

Conclusion As a result of continued follow-up through an outpatient clinic and community-based self-exercise after hospital-based CR in patients with MI, the DM group still had lower exercise capacity than did the nonDM group 1 year after the onset of MI, but both groups maintained their improved exercise capacity following hospital-based CR.

Keywords Diabetes mellitus, Myocardial infarction, Exercise test, Rehabilitation

Received May 14, 2015; Accepted June 19, 2015

Corresponding author: Ji Hee Kim

Department of Rehabilitation Medicine, Wonkwang University School of Medicine and Hospital, 895 Muwang-ro, Iksan 54538, Korea Tel: +82-63-859-0647, Fax: +82-63-843-1385, E-mail: gold82mouse@hanmail.net

(c) This is an open-access article distributed under the terms of the Creative Commons Attribution Non-Commercial License (http://creativecommons.org/ licenses/by-nc/4.0) which permits unrestricted noncommercial use, distribution, and reproduction in any medium, provided the original work is properly cited. Copyright $\odot 2015$ by Korean Academy of Rehabilitation Medicine 


\section{INTRODUCTION}

It is widely understood that diabetic (DM) patients have higher risk of cardiovascular disease than do non-diabetic (non-DM) patients [1]. Because cardiovascular disease is the main cause of mortality in DM patients [2], the disease onset and mortality risk are two to four times higher in DM than in non-DM patients [3,4], and prognosis after myocardial infarction (MI) is worse in DM patients [5-7].

Cardiac rehabilitation (CR) with exercise training after MI significantly reduces cardiovascular morbidity and mortality $[8,9]$, and this type of CR is categorized as a class 1 recommendation in most contemporary cardiovascular clinical practice guidelines [10]. The cardiovascular mortality rate is reported to be $20 \%$ lower in patients who received CR after MI than in those who did not, and it was confirmed by Hedback et al. [11] that cardiovascular mortality and total mortality after CR were reduced in the long term. In addition, the reduced cardiovascular mortality after cardiovascular rehabilitation was still noticeable in patients over 65 years old [12].

Diabetic patients after MI show lower exercise capacity than do non-DM patients $[13,14]$. Cardiovascular rehabilitation through exercise training helps diabetic patients improve their reduced post-MI exercise capacity $[13,15,16]$. However, previous studies demonstrated that the effect of CR was lower among DM than in non-DM patients in relation to exercise capacity after acute ischemic heart disease [17]. Another study with a large group of patients showed relatively similar degrees of exercise capacity improvement in DM and non-DM patients after cardiovascular rehabilitation $[13,18]$. However, most of the research has focused on comparing CR's effects in DM and non-DM patients several weeks to several months after the rehabilitation.

Recently, it was reported that a long-term exercise capacity change had been observed through continued community-based self-exercise in patients who had successfully completed a cardiovascular rehabilitation program after MI. Madssen et al. [19] reported that exercise capacity stayed constant without significant change in patients who continued with community-based self-exercise for a year after the post-MI hospital-based CR compared with the patients who completed only the hospitalbased rehabilitation. However, recent studies have rarely focused on comparing exercise capacity in DM and non-
DM patients through long-term follow-up of patients who continued community-based self-exercise after CR.

The aim of this study is to compare the improvement in exercise capacity after post-MI cardiovascular rehabilitation in DM and non-DM patients; to monitor the duration of the improved exercise capacity through long-term follow-up with patients who continued with communitybased self-exercise and continued to manage risk factors; and, finally, to compare exercise capacity in DM and non-DM patients after a long period of time.

\section{MATERIALS AND METHODS}

\section{Subjects}

Of patients who underwent percutaneous coronary intervention for acute $\mathrm{MI}$ in the department of cardiology in Regional cardiocerebrovascular center of Wonkwang University Hospital from February 2012 to January 2014 and were referred to the Department of Physical Medicine and Rehabilitation afterwards, the subjects over 30 and below 70 years old were selected. With a retrospective review of medical records, the subjects were chosen 1) who had participated in electrocardiography (ECG)monitored exercise at least four to eight times during eight weeks of CR;2) who were followed up by the rehabilitation outpatient clinic for a year without giving up even after they had completed the cardiovascular rehabilitation program; and 3) who had received communitybased self-exercise training.

The following subjects were excluded from the study: those who had a history of acute cardiovascular disease, had a less than $35 \%$ left ventricular ejection fraction, had had coronary artery bypass surgery rather than percutaneous coronary intervention, had uncontrollable arrhythmia or hypertension, stopped participating in the cardiovascular rehabilitation program before eight weeks, failed to follow up within a year despite having completed the hospital-based CR program, or developed a serious disease during the follow-up or during the CR program.

Of 75 patients who received the CR after completing treatment for acute MI, a total of 37 patients satisfied the study criteria; based on the diagnostic criteria for DM, the subjects were divided into Type 2 diabetic patients (DM group, 12 subjects) and non-diabetic patients (nonDM group, 25 subjects). The diagnostic criteria were fast- 
Table 1. Clinical characteristics of the subjects

\begin{tabular}{lcc}
\hline & $\begin{array}{c}\text { DM group } \\
(\mathbf{n = 1 2})\end{array}$ & $\begin{array}{c}\text { Non-DM group } \\
(\mathbf{n = 2 5})\end{array}$ \\
\hline Age $(\mathrm{yr})$ & $57.0 \pm 9.0$ & $55.7 \pm 8.4$ \\
Sex $(\mathrm{men}:$ women$)$ & $10: 2$ & $24: 1$ \\
BMI $\left(\mathrm{kg} / \mathrm{m}^{2}\right)$ & $24.8 \pm 2.3$ & $24.9 \pm 3.1$ \\
\hline LVEF & $52.9 \pm 11.3$ & $50.4 \pm 8.7$ \\
\hline Hypertension & $10(83.3)$ & $17(68.0)$ \\
\hline Hyperlipidemia & $4(33.3)$ & $4(16.0)$ \\
\hline Current smoking & $9(75.0)$ & $13(52.0)$ \\
CHD event type & & \\
\hline STEMI & $9(75.0)$ & $18(72.0)$ \\
\hline NSTEMI & $3(25.0)$ & $7(28.0)$ \\
\hline
\end{tabular}

Values are presented as mean \pm standard deviation or number (\%).

None of the characteristics showed a significant difference between the groups.

DM, diabetes mellitus; BMI, body mass index; LVEF, left ventricular ejection fraction; CHD, coronary heart disease; STEMI, ST elevation myocardial infarction; NSTEMI, non-ST elevation myocardial infarction.

ing plasma glucose above $126 \mathrm{mg} / \mathrm{dL}$; plasma glucose above $200 \mathrm{mg} / \mathrm{dL}$ with common symptoms of diabetes; plasma glucose above $200 \mathrm{mg} / \mathrm{dL}$ after $75 \mathrm{~g}$ of the oral glucose tolerance test; or hemoglobin Alc (HbAlc) above $6.5 \%$ [20]. The average age of the DM group was 57.0 \pm 9.0 years among 10 males and 2 females; the average age of the non-DM group was $55.7 \pm 8.4$ years among 24 males and 1 female. There were no significant differences between the two subject groups in general characteristics (Table 1).

\section{Methods}

After percutaneous coronary intervention, all of the subjects were referred for cardiovascular rehabilitation by the department of physical medicine and rehabilitation and began stretching and indoor walking exercise in the rehabilitation treatment room while receiving education about the cardiovascular rehabilitation program. Indoor walking exercise was done by patients who showed no new or recurrent chest pain or dyspnea within the previous eight hours. During the exercise, the goal was to keep the heart rate below 120 beats per minute, or, if the patient had a high resting heart rate, the goal was to keep the heart rate within 20 beats above the resting rate. The patients were made to walk around the room at first, and then in the corridors for 2 to 5 minutes or so, three to four times a day [21]. After 12 \pm 1.91 days from the onset of MI, the patients visited the physical medicine and rehabilitation outpatient clinic, and a symptom-limited graded exercise tolerance test was administered using the modified Bruce protocol. Examination tools included a realtime recording 12-channel ECG unit (Quinton Q-Stress; Mortara Instrument, Milwaukee, WI, USA), treadmill (QStress TM55, Mortara Instrument), an automatic blood pressure and pulse monitor (247 BP; SunTech Medical, Morrisville, NC, USA), and a respiratory gas analyzer (TrueOne 2400; Parvo Medics, Sandy, UT, USA). Using the ECG and the automatic blood pressure and pulse monitor, maximal exercise time, submaximal rate pressure product at stage $3\left(\mathrm{RPP}_{\text {submax }}\right)$, resting and maximal heart rate, and resting and maximal systolic and diastolic blood pressure were measured; then, using age and maximal heart rate, the percentage of peak heart rate $\left(\% \mathrm{HR}_{\text {peak }}\right)$ was calculated. The $\% \mathrm{HR}_{\text {peak }}$ was calculated by dividing the maximum heart rate by predicted peak heart rate and multiplying that by 100 . Using the respiratory gas analyzer, metabolic equivalent tasks (METs) during the maximal exercise period and peak oxygen consumption $\left(\mathrm{VO}_{2 \text { peak }}\right)$ were measured. Based on results from the exercise tolerance test, the subjects visited the CR clinic and began aerobic exercise training with EGC monitoring. During the exercise training, the Q-Tel RMS (Mortara Instrument) and JT-4000M (Sungdo MC, Siheung, Korea) were used, and exercise intensity was controlled by gradually varying the value from $40 \%$ to $85 \%$ based on the heart rate reserve, which was calculated using patients' resting and maximal heart rates during the incipient exercise tolerance test. One set of exercises consisted of 10 minutes of warm-up, 30 to 40 minutes of prescribed exercise depending on the patient's condition, and $10 \mathrm{~min}$ utes of cool-down, for a total of 50 to 60 minutes; patients visited the clinic and completed the exercise at least four to eight times. The patients were taught to perform community-based self-exercise when they were away from the clinic, and their exercises depended on their individual exercise capacity determined by target heart rate and the rate of perceived exertion based on the exercise tolerance test results. Prescribed exercises included fast walking, power walking, jogging, and bicycling, and muscle strengthening was added four weeks after the dis- 
ease onset. Once the patients had completed eight weeks of $\mathrm{CR}$, the symptom-limited graded exercise tolerance test was re-administered using the modified Bruce protocol. After the hospital-based CR program ended, patients began the graded exercise tolerance test for three months interval through continued follow-up at the rehabilitation department's outpatient clinic, at which time the patients were instructed to continue the community-based self-exercise at least three times a week depending on target heart rate and rate of perceived exertion.

During hospitalization in the cardiology department, all patients received information about MI, including about risk factors, appropriate pharmacologic treatment and exercise training by rehabilitation doctors, nutrition counseling, and anti-smoking education by CR specialized nurses; during follow-up after hospitalization, the patients then received examinations and counseling about their exercise status and how they were managing their risk factors, including not smoking and maintaining healthy nutrition, every three months.

Approximately one year ( $12 \pm 1.23$ months) after the onset of MI, patients took the symptom-limited graded exercise tolerance test. Percent changes in exercise capacity were assessed in both groups to determine differences between before and after one year of CR. The percent changes in each group were calculated by subtracting each patient's exercise capacity before CR from capacity after a year of CR or right after CR, dividing that difference by the before-CR capacity, and, finally multiplying that value by 100. In addition, the study assessed the changes in cardiopulmonary exercise capacity before vs. after the CR and before CR vs. 1 year after the onset of MI. The differences in capacity between groups were also examined at each phase of the CR.

\section{Statistical analysis}

The SPSS statistical program was employed for statistical analysis. The independent-samples t-test was used to compare and analyze the differences between the DM and non-DM groups in age, body mass index, left ventricular ejection fraction, $\mathrm{HbAlc}$, fasting plasma glucose, and cholesterol level. We also analyzed the betweengroup differences in maximal exercise time, resting and maximal systolic and diastolic blood pressure, $\% \mathrm{HR}_{\text {peak }}$, METs during the maximal exercise period, $\mathrm{VO}_{2 \text { peak }}$ before and after CR and 1 year after the onset of MI, and the percent changes in each index. Fisher exact test was used to compare variables between groups by sex, including histories of hypertension and hyperlipidemia. Pearson chi-square test was used to compare the percentages of smoking history and the types of MI across the two groups. The paired-sample t-test was used for the withingroup comparisons of HbAlc, fasting plasma glucose, cholesterol level, and cardiopulmonary exercise capacity before vs. after CR treatment and before CR vs. 1 year after the onset of MI. It was confirmed that all variables showed normal distributions based on the one-sample Kolmogorov-Smirnov test. For statistical significance, pvalue below 0.05 was chosen.

Table 2. Comparison of glucose and lipid profiles between the DM and non-DM groups

\begin{tabular}{|c|c|c|c|c|}
\hline & \multicolumn{2}{|c|}{ DM group $(n=12)$} & \multicolumn{2}{|c|}{ Non-DM group $(n=25)$} \\
\hline & Baseline & After 1 yr & Baseline & After 1 yr \\
\hline HbAlc (\%) & $7.28 \pm 1.30$ & $7.05 \pm 0.97$ & $5.69 \pm 2.27^{b)}$ & $5.52 \pm 0.43^{\mathrm{a}, \mathrm{c})}$ \\
\hline Fasting blood glucose (mg/dL) & $173.25 \pm 43.03$ & $148.25 \pm 39.77$ & $103.60 \pm 12.74^{\mathrm{b})}$ & $101.60 \pm 11.83^{c)}$ \\
\hline Total cholesterol (mg/dL) & $175.50 \pm 40.00$ & $128.25 \pm 25.55^{\mathrm{a})}$ & $190.44 \pm 43.67$ & $147.40 \pm 35.91^{\mathrm{a})}$ \\
\hline $\mathrm{TG}(\mathrm{mg} / \mathrm{dL})$ & $190.50 \pm 158.61$ & $166.25 \pm 105.46$ & $121.00 \pm 80.99$ & $99.56 \pm 47.99^{c)}$ \\
\hline $\mathrm{HDL}-\mathrm{C}(\mathrm{mg} / \mathrm{dL})$ & $41.75 \pm 10.46$ & $41.42 \pm 7.62$ & $46.96 \pm 13.15$ & $51.00 \pm 18.13^{\mathrm{c})}$ \\
\hline $\mathrm{LDL}-\mathrm{C}(\mathrm{mg} / \mathrm{dL})$ & $99.00 \pm 30.51$ & $57.58 \pm 18.53^{\text {a) }}$ & $110.44 \pm 36.41$ & $71.72 \pm 21.39^{a)}$ \\
\hline
\end{tabular}

Values are presented as mean \pm standard deviation.

DM, diabetes mellitus; HbAlc, hemoglobin Alc; TG, triglyceride; HDL-C, high-density lipoprotein cholesterol, LDLC, low-density lipoprotein cholesterol.

${ }^{a)} \mathrm{p}<0.05$ for baseline and after 1 year in each group.

b) $\mathrm{p}<0.05$ for comparing the non-DM and DM groups at baseline.

${ }^{c} \mathrm{p}<0.05$ for comparing the non-DM and DM groups after 1 year. 


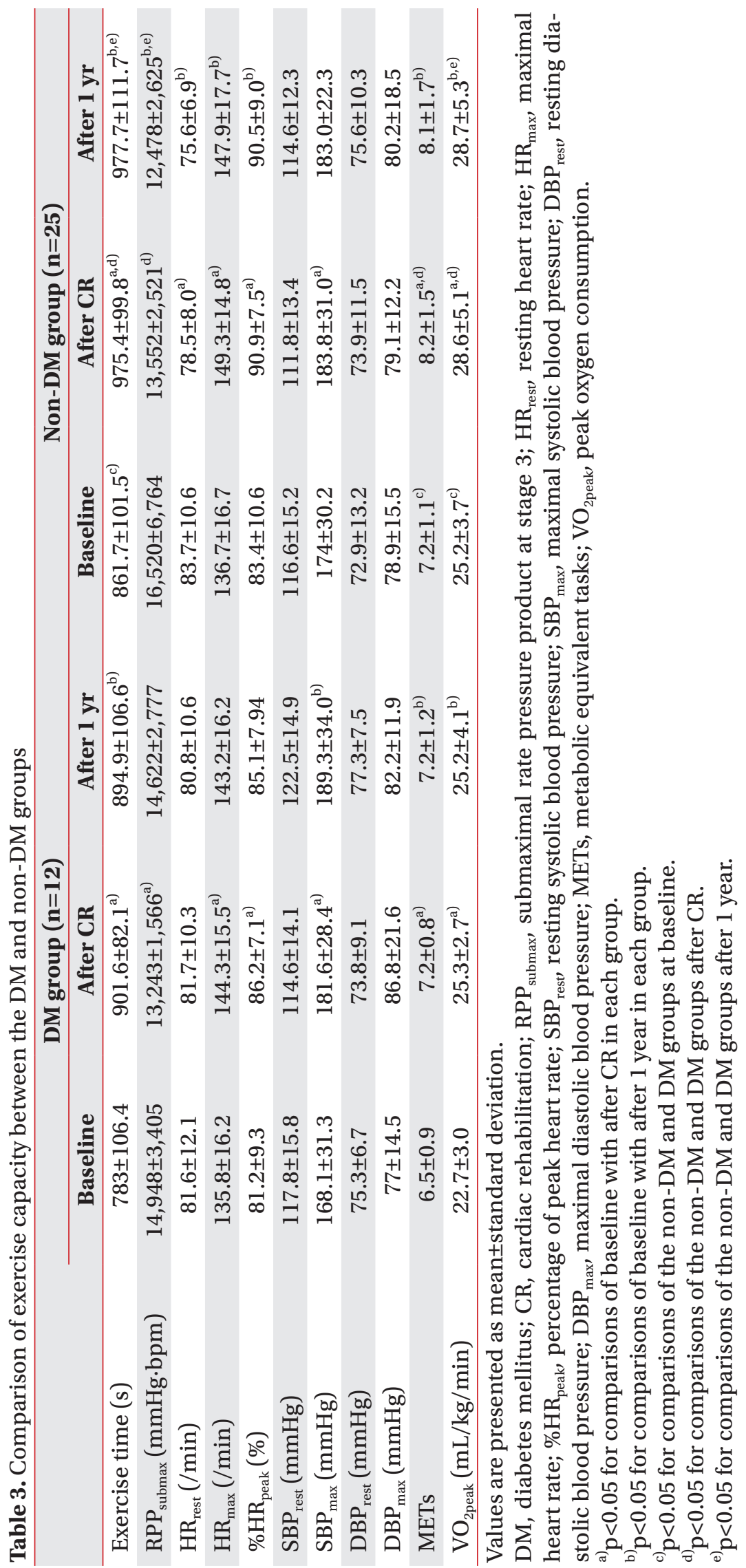




\section{RESULTS}

\section{Patient characteristics}

There were no significant differences between the DM and non-DM patients in body mass index, left ventricular ejection fraction, hypertension and hyperlipidemia, smoking status, or type of MI (Table 1). Of the twelve patients in the DM group, six (50\%) developed newly diagnosed diabetes at the time of the MI, and the average morbidity period was $5.33 \pm 3.64$ years for the original diabetic patients. To treat their diabetes, six patients $(50 \%)$ only went on a diet, and the other six (50\%) received an oral medication.

The DM group had statistically significantly higher $\mathrm{HbAlc}$ and fasting plasma glucose values both before CR and 1 year after the onset of MI than did the non-DM group. The averages for both values were lower in the DM group 1 year after the onset of MI, but no differences were significant (Table 2). There were also no significant differences between the DM and non-DM groups in total cholesterol or low-density lipoprotein (LDL) cholesterol values either before the rehabilitation program or after one year of disease; in both groups, the total and LDL cholesterol values were significantly low one year after the disease onset (Table 2).
Exercise tolerance test results before and after CR and one year after Ml onset

Before the cardiac rehabilitation, the DM group had significantly lower exercise capacity based on exercise times, $\mathrm{VO}_{2 \text { peak }}$, and METs than did the non-DM group. Comparing exercise capacity before and after the CR, both groups showed significantly improved maximal exercise times, heart rate, $\% \mathrm{HR}_{\text {peak }}$, maximal systolic blood pressure, $\mathrm{VO}_{2 \text { peak }}$, and METs. After the $\mathrm{CR}$, the DM group had significantly lower exercise times, $\mathrm{RPP}_{\text {submax }}, \mathrm{VO}_{\text {2peak, }}$, and METs than did the non-DM group (Table 3).

Exercise capacity before CR vs. 1 year after MI onset was significantly improved in both groups in maximal exercise times, $\mathrm{VO}_{\text {2peak }}$, and METs. There were no statistically significant differences in exercise capacity in either group between capacity after CR and 1 year after the onset of MI ( $p>0.05)$. One year after the onset of MI, the DM group showed significantly lower maximal exercise times, $\mathrm{RPP}_{\text {submax }}$, and $\mathrm{VO}_{2 \text { peak }}$ than did the non-DM group (Table 3 ).

Exercise tolerance test result percent changes before and after CR and one year after MI onset

There were no statistically significant differences in the percent changes for any of the exercise capacity variables between the DM and non-DM groups. For the percent

Table 4. Comparison of \% changes in exercise capacity after CR and after 1 year in the DM and non-DM groups

\begin{tabular}{|c|c|c|c|c|}
\hline & \multicolumn{2}{|c|}{ After CR } & \multicolumn{2}{|c|}{ After 1 yr } \\
\hline & DM group $(n=12)$ & Non-DM group $(n=25)$ & DM group $(n=12)$ & Non-DM group $(n=25)$ \\
\hline \% change in exercise time & $16.3 \pm 12.9$ & $14.5 \pm 16.2$ & $15.4 \pm 15.5$ & $14.9 \pm 18.4$ \\
\hline$\%$ change in $\mathrm{RPP}_{\text {submax }}$ & $-7.7 \pm 21.8$ & $-10.8 \pm 24.4$ & $1.0 \pm 24.1$ & $-17.8 \pm 24.9^{a)}$ \\
\hline$\%$ change in $\mathrm{HR}_{\text {rest }}$ & $1.3 \pm 14.0$ & $-5.5 \pm 9.6$ & $0.0 \pm 12.7$ & $-8.7 \pm 10.9$ \\
\hline$\%$ change in $\mathrm{HR}_{\max }$ & $6.7 \pm 8.8$ & $10.1 \pm 12.2$ & $5.9 \pm 10.0$ & $9.0 \pm 13.9$ \\
\hline$\%$ change in $\% \mathrm{HR}_{\text {peak }}$ & $6.7 \pm 8.8$ & $10.1 \pm 12.2$ & $6.5 \pm 10.1$ & $9.7 \pm 13.9$ \\
\hline$\%$ change in $\mathrm{SBP}_{\text {rest }}$ & $-2.2 \pm 8.8$ & $-3.1 \pm 13.3$ & $4.6 \pm 10.3$ & $-0.6 \pm 13.6$ \\
\hline$\%$ change in $\mathrm{SBP}_{\max }$ & $9.2 \pm 13.2$ & $6.7 \pm 13.4$ & $13.6 \pm 14.8$ & $7.5 \pm 18.5$ \\
\hline$\%$ change in $\mathrm{DBP}_{\text {rest }}$ & $-2.0 \pm 9.3$ & $3.9 \pm 23.3$ & $2.7 \pm 6.8$ & $7.1 \pm 26.1$ \\
\hline$\%$ change in $\mathrm{DBP}_{\max }$ & $14.0 \pm 24.2$ & $2.3 \pm 17.0$ & $8.8 \pm 17.6$ & $24.3 \pm 171.9$ \\
\hline$\%$ change in METs & $12.5 \pm 10.8$ & $14.8 \pm 16.9$ & $11.3 \pm 7.9$ & $13.6 \pm 25.0$ \\
\hline$\%$ change in $\mathrm{VO}_{2 \text { peak }}$ & $12.5 \pm 10.2$ & $14.1 \pm 16.7$ & $10.8 \pm 7.7$ & $15.3 \pm 22.5$ \\
\hline
\end{tabular}

Values are presented as mean \pm standard deviation.

$\mathrm{CR}$, cardiac rehabilitation; $\mathrm{DM}$, diabetes mellitus; $\mathrm{RPP}_{\text {submax }}$, submaximal rate pressure product at stage 3; $\mathrm{HR}_{\text {rest }}$, resting heart rate; $\mathrm{HR}_{\max }$, maximal heart rate; $\% \mathrm{HR}_{\text {peak }}$, percentage of peak heart rate; $\mathrm{SBP}_{\text {rest }}$, resting systolic blood pressure; $\mathrm{SBP}_{\text {max }}$, maximal systolic blood pressure; $\mathrm{DBP}_{\text {rest }}$, resting diastolic blood pressure; $\mathrm{DBP}_{\max }$, maximal diastolic blood pressure; METs, metabolic equivalent tasks; $\mathrm{VO}_{2 \text { peak }}$, peak oxygen consumption.

${ }^{a)} \mathrm{p}<0.05$ for comparisons of the non-DM and DM groups. 
changes between before CR and one year after the onset of MI, there were no statistically significant differences between the two groups except for $\mathrm{RPP}_{\text {submax }}$ (Table 4).

\section{DISCUSSION}

It is widely understood that DM patients have relatively lower exercise capacity compared with non-DM patients. Previous research has reported defects in functional exercise capacity in DM patients as assessed by peak oxygen consumption and other measures of cardiovascular exercise performance [22-25]. Exercise capacity defects in DM patients are caused by multiple mechanisms, including insulin resistance, endothelial dysfunction, decreased myocardial perfusion, decreased tissue hemoglobin oxygen saturation, and impaired mitochondrial function [26-28]. For these patients, exercise capacity defects can be improved through exercise training, and Boule et al. [14] reported that DM patients who completed more than eight weeks of a structured aerobic exercise intervention showed $11.8 \%$ improvement in peak oxygen consumption. This is a clinically important result because another study demonstrated that if peak oxygen consumption increased by $1.44 \mathrm{~mL} / \mathrm{kg} / \mathrm{min}$, overall mortality decreased by $7.9 \%$ [29]. In addition, for DM patients, exercise training improves glucose metabolism, insulin signaling, lipid profile, endothelial function, and blood pressure as well as exercise tolerance [23]. Hindman at al. [16] reported a decrease in fasting glucose and a significant improvement in blood cholesterol in DM patients who participated in a CR program after the onset of MI. Similarly, we showed improved glucose metabolism, lipid metabolism, and, especially, total and LDL cholesterol with continued hospital-based CR and community-based self-exercise 1 year after the onset of MI. However, in this study, all subjects continued to take an anti-hyperlipidemic agent after the stent insertion, and because the study comparisons did not include a subject group that did not perform the exercise, it was unclear whether the improved lipid metabolism was the effect of medications or of exercise.

Previous studies have reported that DM patients had lower exercise capacity after MI than did non-DM patients $[13,14]$, and a large cohort study reported that low exercise capacity in DM patients was a strong and independent predictor of long-term mortality in heart disease patients $[30,31]$. In contrast, improved exercise capacity was related to subsequent lower mortality in DM patients. $[29,32]$. The CR through exercise training helped to improve the maximal aerobic capacity in DM patients. Banzer et al. [13] and Milani and Lavie [15] reported, respectively, that METs increased in DM patients by $26 \%$ and $38 \%$ through CR after coronary artery disease. Additionally, Hindman et al. [16] reported a $26.3 \%$ increase in METs in DM patients who participated in post-MI CR for 7 to 12 weeks.

Based on the current studies, the differences in improved exercise capacity following CR between DM and non-DM patients are unclear. Although previous studies reported less improvement in cardiopulmonary exercise capacity through CR after acute ischemic heart disease in DM patients than in non-DM patients $[17,33,34]$, another study demonstrated that the improvement was greater in DM than non-DM patients [15], and other studies found the degrees of improvement to be similar between DM and non-DM patients $[13,18]$. In the current study, when $\mathrm{DM}$ and non-DM patients underwent $\mathrm{CR}$ after the onset of MI, both groups showed significantly improved cardiopulmonary exercise capacity after CR. When Mourot et al. [18] compared capacity after CR in DM and nonDM patients, both groups showed significant and similar degrees of improvement, but exercise capacity was still low in the DM patients. This result was consistent with our results in that we found no difference in the percent change in exercise capacity between the DM and nonDM patients before and after CR and the DM patients' post-CR exercise capacity was statistically significantly lower than that of the non-DM patients. However, one difference between other research and ours is that Mourot et al. [18] found respective changes in peak oxygen consumption of $28 \%$ and $31 \%$ in the DM and non-DM patients, but in this study, the changes were lower, $12.5 \%$ and $14.1 \%$. These differences could be attributed to the differences in the CR that was administered. The patients in Mourot et al. [18] received exercise training supervised by a physical therapist five times a week for six weeks, whereas this study administered hospital-based ECGmonitored exercise four to eight times per week during eight weeks of community-based self-exercise. Hammill et al. [35], in a study of CR and mortality in MI patients, found a strong dose-response relationship between the number of CR sessions and the long-term prognosis. In other words, in this study, the small changes before and 
after CR might have been because this study's patients exercised relatively less frequently than did the patients in Mourot et al. [18].

In this study, a graded exercise tolerance test was administered every 3-month follow-ups after eight weeks of the hospital-based CR program; after the continued community-based self-exercise education and instruction on managing risk factors, exercise capacity was significantly high 1 year after the onset of MI in both the DM and non-DM patients compared with their capacities before CR. Throughout one year of outpatient clinic follow-up for 49 patients who completed hospital-based CR after coronary artery disease, Madssen et al. [19] studied the changes in exercise capacity between those who underwent the CR intervention and those who did not. That study reported that peak oxygen consumption did not change significantly in either group compared with before the CR. In the current study, there were no statistically significant differences in either group between after the CR and 1 year after the onset of the MI, and both groups maintained their improved exercise capacity for up to one year. To explain the lack of post-intervention improvement in exercise capacity for the intervention group, Madssen et al. [19] suggested that infrequent exercise sessions in which patients maintained life-long community-based self-exercise following once-monthly hospital-supervised exercise was not actually effective in improving exercise capacity. Based on this suggestion, we believed that our community-based self-exercise program was also inadequate for improving exercise capacity.

To date, many studies have compared and analyzed changes in exercise capacity after CR treatment that lasted from a few weeks to several months in both DM and non-DM patients. However, few studies have compared the exercise capacity of DM and non-DM patients through long-term follow-up after CR. In this study, the exercise capacity of both patient groups was examined 1 year after the onset of MI, and it was statistically significantly low in the DM patients. That is, exercise capacity improved after the hospital-based CR and through the ongoing community-based self-exercise after the end of the hospital rehabilitation, but the DM patients still had lower exercise capacities than did the non-DM patients. Therefore, when a DM patient's cardiopulmonary exercise capacity decreases following MI, a continued decrease in long-term exercise capacity in these patients should be expected, but the advantages of $\mathrm{CR}$, such as increased exercise capacity and reduced mortality, should be emphasized in order to encourage participation in a CR program. Specifically, it seems necessary to foster more active and longer-term CR of high intensity and high frequency to manage risk factors and increase rigorous self-exercise.

In this study, results similar to those from other studies were confirmed for different variables such as $\mathrm{VO}_{\text {2peak }}$ after CR. METs are also important predictors of exercise capacity; they increased significantly in both DM and non-DM patients after CR in this study, and a separate study showed that mortality decreased by $13 \%$ when MET increased by $1 \%$, a meaningful result [36]. After CR, maximal heart rate significantly increased in both DM and non-DM patients, and $\% \mathrm{HR}_{\text {peak }}$ also significantly increased when considering patient age. Lauer et al. [37] reported that the total mortality was low when the maximal heart rate was high in a study that examined the relationship between total mortality and maximal heart rate during the exercise tolerance test, and the observation that maximal heart rate increased after CR offers hope for positive prognoses.

Of the exercise indexes that were used in this study, $\mathrm{RPP}_{\text {submax }}$ showed a different response from the others. In non-DM patients, $\mathrm{RPP}_{\text {submax }}$ continued to improve 1 year after MI onset and demonstrated a significant difference, but no continued improvement was shown in the DM patients (Table 3). As a result, there was a significant difference between the groups in the percent change in $\mathrm{RPP}_{\text {submax }}$, unlike the percent changes for the other indexes of exercise capacity 1 year after the MI (Table 4). This finding implies that diabetes may impede improving $\mathrm{RPP}_{\text {submax }}$, and a more thorough study is considered necessary for detailing the effects of diabetes on RPP and its mechanism.

The first limitation of the current study was the insufficient number of patients. Second, because all patients received percutaneous coronary intervention before their CR referrals, this study's results cannot be applied to patients who underwent coronary artery bypass surgery. Third, although the education on maintaining community-based self-exercise following eight weeks of the hospital-based CR was continuous and the outpatient clinic reported that the patients regularly performed appropri- 
ate exercises, exact exercise intensity and frequency were not recorded. Fourth, patients were excluded who were not observed at follow-up after the hospital-based CR or who did not perform the community-based self-exercise. Thus, a future study should consist of long-term research that covers many more patients and more comprehensive variations of coronary artery disease.

In conclusion, following acute MI, diabetic patients had lower exercise capacity than did non-diabetic patients. When they completed the hospital-based cardiac rehabilitation for 8 weeks after the onset of acute MI, both groups showed significantly improved exercise capacity, but the DM patients still had lower capacity than the non-DM patients. When risk factor management and community-based self-exercise continued after the hospital-based CR, the DM patients showed lower exercise capacity than the non-DM patients even 1 year after the onset of MI, but they did maintain their improved capacity. Thus, more active and long-term CR must be developed for DM patients.

\section{CONFLICT OF INTEREST}

No potential conflict of interest relevant to this article was reported.

\section{ACKNOWLEDGMENTS}

This paper was supported by the Wonkwang Institute of Clinical Medicine in 2015.

\section{REFERENCES}

1. Haffner SM, Lehto S, Ronnemaa T, Pyorala K, Laakso M. Mortality from coronary heart disease in subjects with type 2 diabetes and in nondiabetic subjects with and without prior myocardial infarction. N Engl J Med 1998;339:229-34.

2. Kannel WB. Lipids, diabetes, and coronary heart disease: insights from the Framingham Study. Am Heart J 1985;110:1100-7.

3. Garcia MJ, McNamara PM, Gordon T, Kannel WB. Morbidity and mortality in diabetics in the Framingham population. Sixteen year follow-up study. Diabetes 1974;23:105-11.

4. Rytter L, Troelsen S, Beck-Nielsen H. Prevalence and mortality of acute myocardial infarction in patients with diabetes. Diabetes Care 1985;8:230-4.

5. Abbud ZA, Shindler DM, Wilson AC, Kostis JB. Effect of diabetes mellitus on short- and long-term mortality rates of patients with acute myocardial infarction: a statewide study. Myocardial Infarction Data Acquisition System Study Group. Am Heart J 1995;130:51-8.

6. Behar S, Boyko V, Reicher-Reiss H, Goldbourt U. Ten-year survival after acute myocardial infarction: comparison of patients with and without diabetes. Secondary Prevention Reinfarction Israeli Nifedipine Trial. Am Heart J 1997;133:290-6.

7. Zuanetti G, Latini R, Maggioni AP, Santoro L, Franzosi MG. Influence of diabetes on mortality in acute myocardial infarction: data from the GISSI-2 study. J Am Coll Cardiol 1993;22:1788-94.

8. Oldridge NB, Guyatt GH, Fischer ME, Rimm AA. Cardiac rehabilitation after myocardial infarction. Combined experience of randomized clinical trials. JAMA 1988;260:945-50.

9. O'Connor GT, Buring JE, Yusuf S, Goldhaber SZ, Olmstead EM, Paffenbarger RS Jr, et al. An overview of randomized trials of rehabilitation with exercise after myocardial infarction. Circulation 1989;80:234-44.

10. Wenger NK. Current status of cardiac rehabilitation. J Am Coll Cardiol 2008;51:1619-31.

11. Hedback B, Perk J, Wodlin P. Long-term reduction of cardiac mortality after myocardial infarction: 10-year results of a comprehensive rehabilitation programme. Eur Heart J 1993;14:831-5.

12. Suaya JA, Stason WB, Ades PA, Normand SL, Shepard DS. Cardiac rehabilitation and survival in older coronary patients. J Am Coll Cardiol 2009;54:25-33.

13. Banzer JA, Maguire TE, Kennedy CM, O'Malley CJ, Balady GJ. Results of cardiac rehabilitation in patients with diabetes mellitus. Am J Cardiol 2004;93:81-4.

14. Boule NG, Kenny GP, Haddad E, Wells GA, Sigal RJ. Meta-analysis of the effect of structured exercise training on cardiorespiratory fitness in Type 2 diabetes mellitus. Diabetologia 2003;46:1071-81.

15. Milani RV, Lavie CJ. Behavioral differences and effects of cardiac rehabilitation in diabetic patients following cardiac events. Am J Med 1996;100:517-23.

16. Hindman L, Falko JM, LaLonde M, Snow R, CaulinGlaser T. Clinical profile and outcomes of diabetic and nondiabetic patients in cardiac rehabilitation. Am 
Heart J 2005;150:1046-51.

17. Verges B, Patois-Verges B, Cohen M, Lucas B, GallandJos C, Casillas JM. Effects of cardiac rehabilitation on exercise capacity in Type 2 diabetic patients with coronary artery disease. Diabet Med 2004;21:889-95.

18. Mourot L, Boussuges A, Maunier S, Chopra S, Riviere F, Debussche X, et al. Cardiovascular rehabilitation in patients with diabetes. J Cardiopulm Rehabil Prev 2010;30:157-64.

19. Madssen E, Arbo I, Granoien I, Walderhaug L, Moholdt T. Peak oxygen uptake after cardiac rehabilitation: a randomized controlled trial of a 12-month maintenance program versus usual care. PLoS One 2014;9:e107924.

20. American Diabetes Association. Executive summary: standards of medical care in diabetes, 2012. Diabetes Care 2012;35 Suppl 1:S4-S10.

21. Contractor AS. Cardiac rehabilitation after myocardial infarction. J Assoc Physicians India 2011;59 Suppl:51-5.

22. Schneider SH, Amorosa LF, Khachadurian AK, Ruderman NB. Studies on the mechanism of improved glucose control during regular exercise in type 2 (non-insulin-dependent) diabetes. Diabetologia 1984;26:35560.

23. Bauer TA, Reusch JE, Levi M, Regensteiner JG. Skeletal muscle deoxygenation after the onset of moderate exercise suggests slowed microvascular blood flow kinetics in type 2 diabetes. Diabetes Care 2007;30:28805.

24. Brandenburg SL, Reusch JE, Bauer TA, Jeffers BW, Hiatt WR, Regensteiner JG. Effects of exercise training on oxygen uptake kinetic responses in women with type 2 diabetes. Diabetes Care 1999;22:1640-6.

25. Nadeau KJ, Regensteiner JG, Bauer TA, Brown MS, Dorosz JL, Hull A, et al. Insulin resistance in adolescents with type 1 diabetes and its relationship to cardiovascular function. J Clin Endocrinol Metab 2010;95:513-21.

26. Boirie Y, Short KR, Ahlman B, Charlton M, Nair KS. Tissue-specific regulation of mitochondrial and cytoplasmic protein synthesis rates by insulin. Diabetes 2001;50:2652-8.
27. Kelley DE, He J, Menshikova EV, Ritov VB. Dysfunction of mitochondria in human skeletal muscle in type 2 diabetes. Diabetes 2002;51:2944-50.

28. Reusch JE, Bridenstine M, Regensteiner JG. Type 2 diabetes mellitus and exercise impairment. Rev Endocr Metab Disord 2013;14:77-86.

29. Blair SN, Kohl HW 3rd, Barlow CE, Paffenbarger RS Jr, Gibbons LW, Macera CA. Changes in physical fitness and all-cause mortality: a prospective study of healthy and unhealthy men. JAMA 1995;273:1093-8.

30. Wei M, Gibbons LW, Kampert JB, Nichaman MZ, Blair SN. Low cardiorespiratory fitness and physical inactivity as predictors of mortality in men with type 2 diabetes. Ann Intern Med 2000;132:605-11.

31. Myers J, Prakash M, Froelicher V, Do D, Partington S, Atwood JE. Exercise capacity and mortality among men referred for exercise testing. $N$ Engl J Med 2002;346:793-801.

32. Erikssen G, Liestol K, Bjornholt J, Thaulow E, Sandvik $\mathrm{L}$, Erikssen J. Changes in physical fitness and changes in mortality. Lancet 1998;352:759-62.

33. Camerini A, Chieffo C, Griffo R, Comaschi M, Gattone M, Mannucci E, et al. Recommendations for cardiovascular rehabilitation in diabetes mellitus. Monaldi Arch Chest Dis 2003;60:263-82.

34. Suresh V, Harrison RA, Houghton P, Naqvi N. Standard cardiac rehabilitation is less effective for diabetics. Int J Clin Pract 2001;55:445-8.

35. Hammill BG, Curtis LH, Schulman KA, Whellan DJ. Relationship between cardiac rehabilitation and long-term risks of death and myocardial infarction among elderly Medicare beneficiaries. Circulation 2010;121:63-70.

36. Hung RK, Al-Mallah MH, McEvoy JW, Whelton SP, Blumenthal RS, Nasir K, et al. Prognostic value of exercise capacity in patients with coronary artery disease: the FIT (Henry Ford ExercIse Testing) project. Mayo Clin Proc 2014;89:1644-54.

37. Lauer MS, Okin PM, Larson MG, Evans JC, Levy D. Impaired heart rate response to graded exercise: prognostic implications of chronotropic incompetence in the Framingham Heart Study. Circulation 1996;93:1520-6. 